\title{
LOW TEMPERATURE FIRING OF Pb-CONTAINED THICK FILM DIELECTRICS
}

\author{
SHEN-LI FU and GUNG-FUN CHEN \\ Department of Electrical Engineering, National Cheng Kung University, Tainan, Taiwan, Republic of China
}

\begin{abstract}
The preparation and properties of the $\mathrm{Pb}\left(\mathrm{Fe}_{2 / 3} \mathrm{~W}_{1 / 3}\right)_{\mathrm{x}}\left(\mathrm{Fe}_{1 / 2} \mathrm{Nb}_{1 / 2}\right)_{0.86-\mathrm{x}} \mathrm{Ti}_{0.14} \mathrm{O}_{3}$-based thick film dielectrics are described. The Calcined $\mathrm{Pb}\left(\mathrm{Fe}_{2 / 3} \mathrm{~W}_{1 / 3}\right) \mathrm{O}_{3}$ powder, instead of glass frit, is used as the flux agent to promote densification during the firing process. Firing is conducted at temperatures below $1000^{\circ} \mathrm{C}$. The dissolution of $\mathrm{Pb}\left(\mathrm{Fe}_{2 / 3} \mathrm{~W}_{1 / 3}\right) \mathrm{O}_{3}$ into the starting material and the segregation of $\mathrm{Pb}\left(\mathrm{Fe}_{2 / 3} \mathrm{~W}_{1 / 3}\right) \mathrm{O}_{3}$ along the grain boundaries result in two peaks in the dielectric constant vs temperature behaviour. By controlling the amount of $\mathrm{Pb}\left(\mathrm{Fe}_{2 / 3} \mathrm{~W}_{1 / 3}\right) \mathrm{O}_{3}$ appropriately, the temperature coefficient of capacitance may be improved. The average dielectric constant of the compositions prepared range from 783 to 1639 at $1 \mathrm{KHz}$. The loss factor can be reduced by adding small amounts of $\mathrm{MnO}_{2}$, and is below $2 \%$ at $1 \mathrm{KHz}$ from $-25^{\circ} \mathrm{C}$ to $+85^{\circ} \mathrm{C}$. Microscopic observation and $\mathrm{x}$-ray diffraction analysis have also been conducted to confirm the mechanism deduced for explaining the results.
\end{abstract}

\section{INTRODUCTION}

In recent years, the trend in electronic circuit miniaturization has continued using hybrid microelectronic circuits. For capacitors in hybrid circuit modules, either multilayered ceramic capacitors (MLCs) or thick film capacitors may be selected. Thick film capacitors are normally uneconomic in hybrid circuits due to a) low $\mathrm{k}, \mathrm{b}$ ) moisture sensitivity, c) "real estate" due to a) and d), poor cumulative yield in a multistage process. In cases where large capacitance and high volumetric efficiency are not the main concerns, thick film capacitors may be superior to MLCs because of the simple production process and low cost.

Most of the commercial high dielectric constant (Hi-K) thick film dielectric pastes were formulated with $\mathrm{BaTiO}_{3}$-based dielectric powder and sintering agents such as glass frits [1]. But the presence of the low dielectric constant (Lo-K) glass frit phase with dielectric constant about 20-30 times less than $\mathrm{BaTiO}_{3}$ would bring a decrease in the effective dielectric constant and the resultant thick film capacitor thus possesses low capacitance density. Firing temperatures of about $1000^{\circ} \mathrm{C}$, if less glass frit was incorporated to achieve a higher capacitance density, make it necessary to use noble metals such as platinum or palladium as electrode materials. Hence, from an economic point of view, the development of a low temperature firing $\mathrm{Hi}-\mathrm{K}$ dielectric paste is essential.

In 1984, T.C. Releiy et al had dealt with this subject and used $\mathrm{PbO}$ as a flux agent to promote the densification of $\mathrm{Pb}(\mathrm{FeNb}) \mathrm{O}_{3} \mathrm{~Pb}(\mathrm{FeW}) \mathrm{O}_{3}$ [2]. However, the firing period of several hours made it impractical for use in conventional thick film capacitor applications.

The composition of $\mathrm{Pb}\left(\mathrm{Fe}_{2 / 3} \mathrm{~W}_{1 / 3}\right)_{\mathrm{x}}\left(\mathrm{Fe}_{1 / 2} \mathrm{Nb}_{1 / 2}\right)_{0.86-\mathrm{x}} \mathrm{Ti}_{0.14} \mathrm{O}_{3}$ (hereafter abbreviated as $\mathrm{PF}(\mathrm{W} / \mathrm{N}) \mathrm{T})$, has been studied previously by the authors as a low temperature firing dielectric for MLC and has given successful results [3]. This ternary dielectric system could be sintered at temperatures of $850-930^{\circ} \mathrm{C}$ for two hours, and possesses a dielectric constant of $13000-32000$ with a loss factor smaller than $1 \%$ around room temperature.

In this study, thick film dielectric pastes, that can be fired at temperatures lower than $1000^{\circ} \mathrm{C}$, have been prepared with $\mathrm{PF}(\mathrm{W} / \mathrm{N}) \mathrm{T}$-based dielectric powders. Instead of glass, one of the constituents of $\mathrm{PF}(\mathrm{W} / \mathrm{N}) \mathrm{T}, \mathrm{Pb}\left(\mathrm{Fe}_{2 / 3} \mathrm{~W}_{1 / 3}\right) \mathrm{O}_{3}$, is selected as a flux agent. Small amounts of $\mathrm{MnO}_{2}$ are also incorporated into the thick film dielectric to reduce the loss factor. $\mathrm{The} \mathrm{Pb}-$ containing composition has then been developed as a low temperature firing thick film dielectric. 


\section{EXPERIMENTAL PROCEDURE}

\subsection{Dielectric Paste}

The raw materials used to formulate the functional powder of $\mathrm{PF}(\mathrm{W} / \mathrm{N}) \mathrm{T}$ are reagent grade $\mathrm{PbO}, \mathrm{Fe}_{203}, \mathrm{Nb}_{2 \mathrm{O}}, \mathrm{W}_{3}$ and $\mathrm{TiO}_{2}$, all with purity of $99.1 \%$ and above. Before forming the $\mathrm{PF}(\mathrm{W} / \mathrm{N}) \mathrm{T}$ ternary system, the compositions of $\mathrm{Pb}\left(\mathrm{Fe}_{1 / 2} \mathrm{Nb}_{1 / 2}\right) \mathrm{O}_{3}, \mathrm{PbTiO}_{3}$ and $\mathrm{Pb}\left(\mathrm{Fe}_{2 / 3} \mathrm{~W}_{1 / 3}\right) \mathrm{O}_{3}$ are prepared. Pyrochlore-free $\mathrm{Pb}\left(\mathrm{Fe}_{1 / 2} \mathrm{Nb}_{1 / 2}\right) \mathrm{O}_{3}$ is obtained by a "Novel" fabrication technique [4] or a double calcination process [5]. After weighing, using appropriate mole ratios, powders of $\mathrm{Pb}\left(\mathrm{Fe}_{2 / 3} \mathrm{~W}_{1 / 3}\right) \mathrm{O}_{3}$ (hereafter abbreviated as $\mathrm{PFW}$ ), $\mathrm{Pb}\left(\mathrm{Fe}_{1 / 2} \mathrm{Nb}_{1 / 2}\right) \mathrm{O}_{3}$ and $\mathrm{PbTiO}_{3}$ are wet-mixed in a ball mill with acetone for six hours. The dried powders are then calcined in a covered alumina crucible at $750^{\circ} \mathrm{C}$ for two hours. This is followed by grinding and sieving with a 325 -mesh screen to give the $\mathrm{PF}(\mathrm{W} / \mathrm{N}) \mathrm{T}$ dielectric powder.

To form the final dielectric paste the flux agent used in this study, PFW, is calcined at $680^{\circ} \mathrm{C}$ for two hours, and then ground and sieved with a 325-mesh screen. The thick film dielectric pastes are fabricated by mixing suitable amounts of $\mathrm{PF}(\mathrm{W} / \mathrm{N}) \mathrm{T}$ functional powder, PFW flux agent, $\mathrm{MnO}_{2}$ and organic vehicles. The flow chart of the overall procedures of paste preparation is given in Fig. 1. The compositions used in this report are listed in Table I.

\subsection{Thick Film Capacitors}

Sandwich type thick film capacitors are fabricated on $96 \% \mathrm{Al}_{2} \mathrm{O}_{3}$ substrates using the abovementioned dielectric paste. A 200-mesh stainless screen is used in the screen printing, and a "triple-printing" process is adopted in depositing the dielectric layer, i.e., three "printinglevelling-drying" cycles are used in depositing each dielectric layer. The alumina substrate is rotated $180^{\circ}$, after each "printing-levelling-drying" cycle, to minimize the possible occurrence of pinhole defects. The conductor electrodes used in this study are of $\mathrm{Pd} / \mathrm{Ag}$.

The as-printed thick film capacitors are fired in a belt furnace with peak firing temperatures set at $900-970^{\circ} \mathrm{C}$ for 15 minutes. The fabricated thick film capacitors are encapsulated with epoxy resin to prevent them from deteriorating in air.

\subsection{Measurement}

The values of capacitances and loss factors of the fabricated thick film capacitors are measured with an automatic capacitance bridge (HP4270A). Scanning electron microscopy observations and x-ray diffraction analyses have also been conducted on the fired dielectric films to obtain an in-depth understanding of the effect of PFW on the dielectric properties of the fired dielectrics.

\section{RESULTS AND DISCUSSIONS}

\subsection{Microscopy Observations}

The microstructure of the fractured cross-section of the \#1 dielectric film (see Table I) fired at $930^{\circ} \mathrm{C}$ is shown in Fig. 2. The picture shown in Fig. 3(a) is the free surface microstructure of the PFW, fired at $900^{\circ} \mathrm{C}$, which shows hexagonal plates with rather uniform geometry. In Fig. 3(b), there is shown the free surface of the \#4 dielectric film, fired at $900^{\circ} \mathrm{C}$. The grain growth produced during the firing process can be seen from Fig. 2. In Fig. 3(b), one can still observe some hexagonal plate-like PFW phase. Thus, it can be postulated that some of the PFW has dissolved and acted as a flux agent in a similar way to glass frits thus promoting the sintering process in a manner similar to that of activated sintering [6]. 


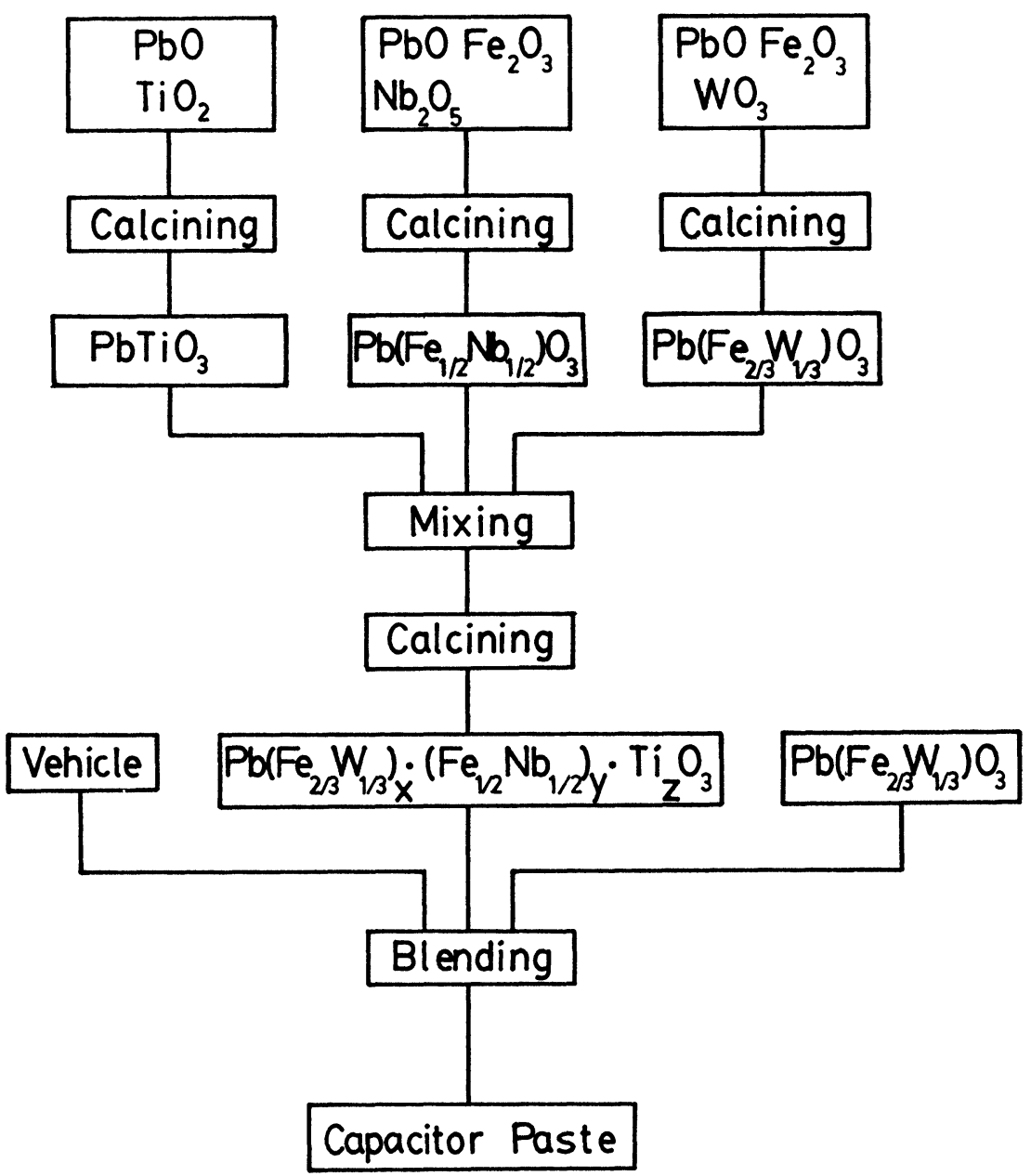

FIGURE 1 Flow chart for dielectric paste preparation.

TABLE I

Compositions used in this work.

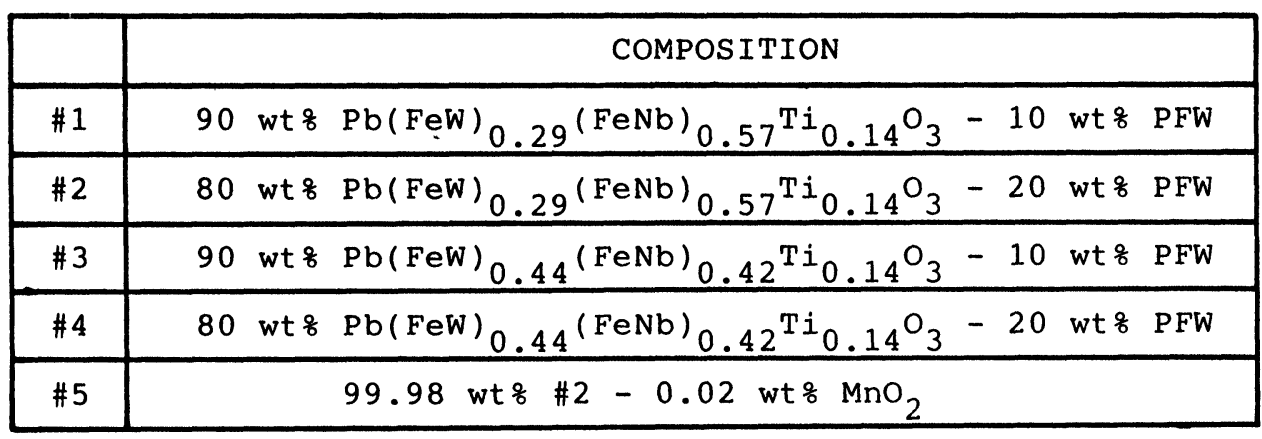




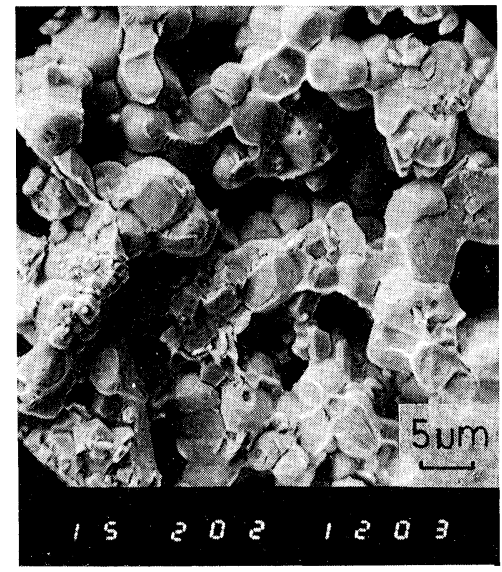

FIGURE 2 Fractured cross section observation of \#1 dielectric film.
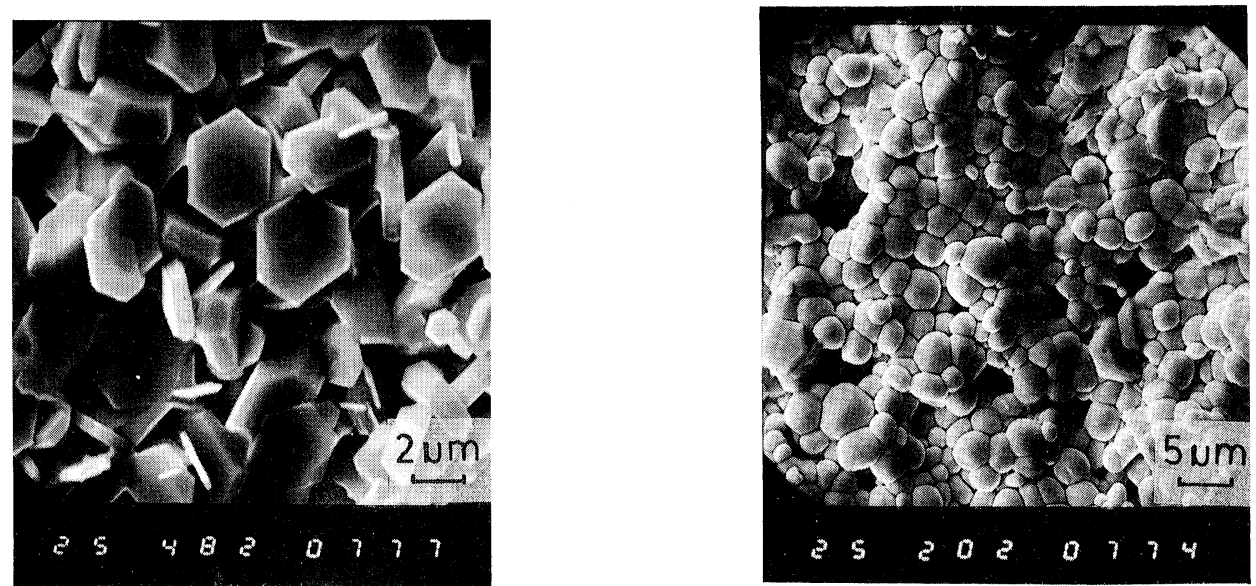

FIGURE 3 Free surface observation of (a) PFW and (b) \#4 dielectric film.

\subsection{Dielectric Properties}

The temperature dependences of both the dielectric constant and dissipation factor of $\mathrm{PF}(\mathrm{W} / \mathrm{N}) \mathrm{T}$ in ceramic form, with $\mathrm{X}=0.44$ and 0.29 , are shown as curve (a) and (b) in Fig. 4. A rather high dielectric constant and a considerable dependence on temperature are observed. The dielectric constant will be decreased, however, by incorporating PFW into the $\mathrm{PF}(\mathrm{W} / \mathrm{N}) \mathrm{T}$ and fabricating into thick film capacitor form.

Fig. 5 shows the temperature dependences of the dielectric constant for (a) \#1, (b) \#2, (c) \#3 and (d) \#4 dielectrics (see Table I) all fired at $930^{\circ} \mathrm{C}$ for 15 minutes. The Curie temperature of $\mathrm{PF}(\mathrm{W} / \mathrm{N}) \mathrm{T}$ with $\mathrm{x}=0.29$, after mixing with $10 \mathrm{wt} \%$ and $20 \mathrm{wt} \% \mathrm{PFW}$, shifts from $60^{\circ} \mathrm{C}$ to $40^{\circ} \mathrm{C}$ and $25^{\circ} \mathrm{C}$, respectively. Such shifts of Curie temperature, when examined together with the microscopic observation of Fig. 3(b) and the fact that the Curie 


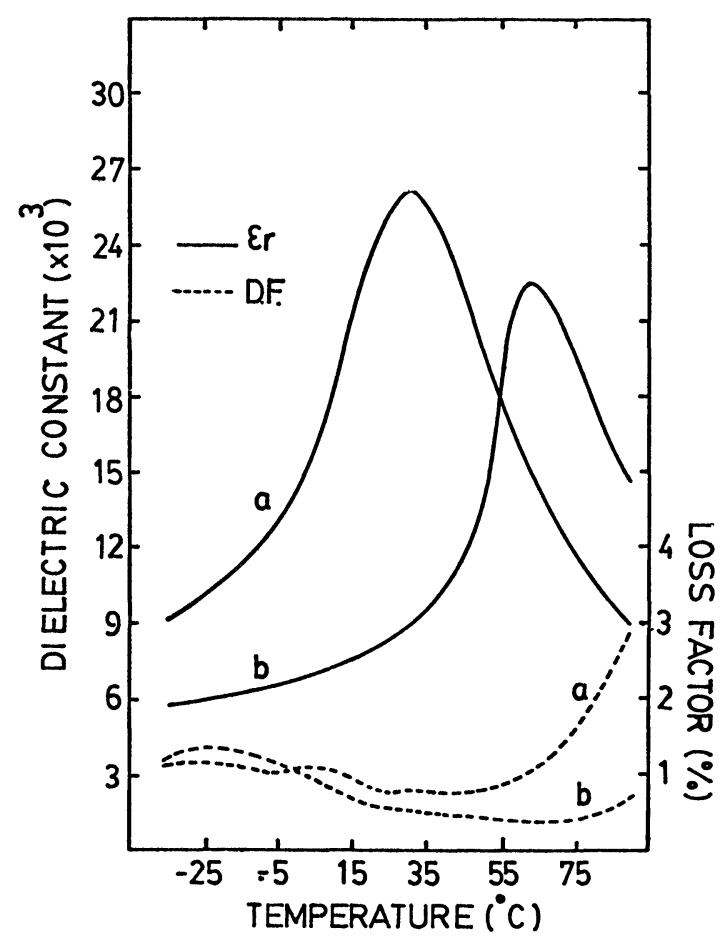

FIGURE 4 Temperature dependence of dielectric constant and dissipation factor for ceramic $\mathrm{PF}(\mathrm{W} / \mathrm{N}) \mathrm{T}$ with $\mathrm{x}=$ 0.44 (curve a) and $\mathrm{x}=0.29$ (curve b) at $1 \mathrm{KHz}$.

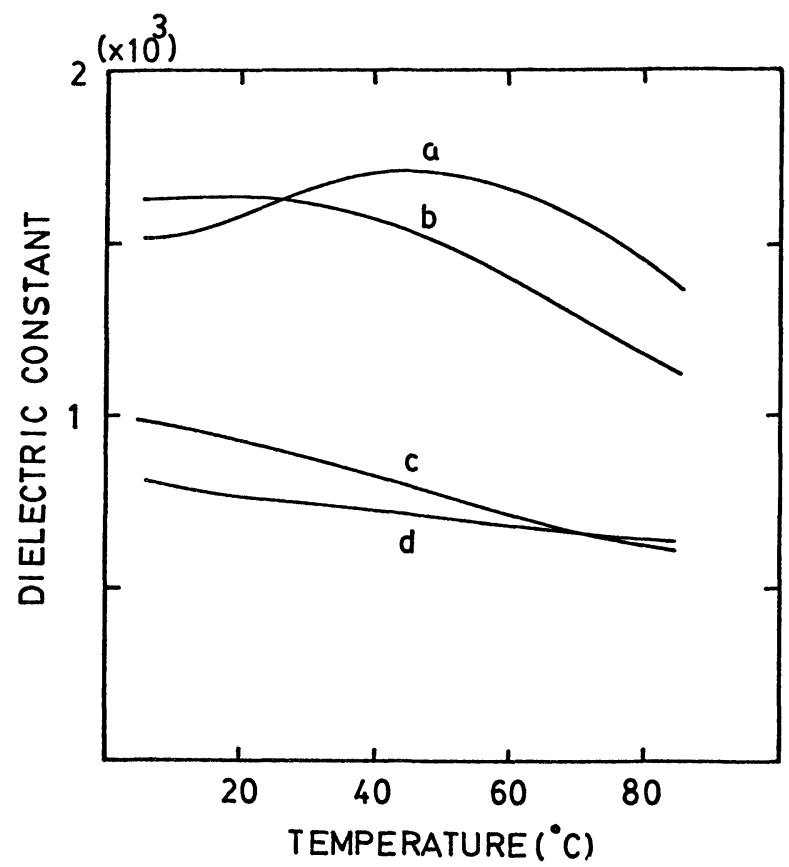

FIGURE 5 Temperature dependence of dielectric constant for (a) \#1 (b) \#2 (c) \#3 and (4) \#4 at $1 \mathrm{KHz}$. 
temperature of $\mathrm{PFW}$ is $-95^{\circ} \mathrm{C}$, [7] may be attributed to the dissolution of some of the PFW into the $\mathrm{PF}(\mathrm{W} / \mathrm{N}) \mathrm{T}$. The higher the content of PFW in the thick film dielectric paste, the lower the Curie temperature of the resultant thick film dielectric will be.

Broadening of the peak in dielectric constant (the broadening effect) is also observed in Fig. 5. This effect is taken to be the consequence of diffuse phase transition (DPT) [8]. In thick film dielectrics, compositional fluctuation is enhanced by incorporating PFW. Owing to the short firing period of 15 minutes, it is impossible for PFW to dissolve into the $\mathrm{PF}(\mathrm{W} / \mathrm{N}) \mathrm{T}$ grain completely and uniformly. Therefore the DPT becomes more pronouned with an increasing amount of PFW incorporated into the thick film dielectric.

The temperature coefficient of capacitance (TCC) vs temperature is shown in Fig. 6 where the broadening due to DPT is again apparent. The percentage variations of capacitance with temperature, expressed as the temperature coefficient of capacitance (TCC), can be seen to be changed from between $+3 \%$ and $-12 \%$ (curve (a), Fig. 6). For the composition to be used a small TCC is required. It can be seen that the capacitance variation versus temperature characteristics can be improved by selecting complex compound perovskite dielectrics of the type discussed.

The dielectric properties of the compositions used in this work are listed in Table II.

The effects of the peak firing temperature on the dielectric properties are shown in Fig. 7. The increase of dielectric constant with peak firing temperature is associated with the

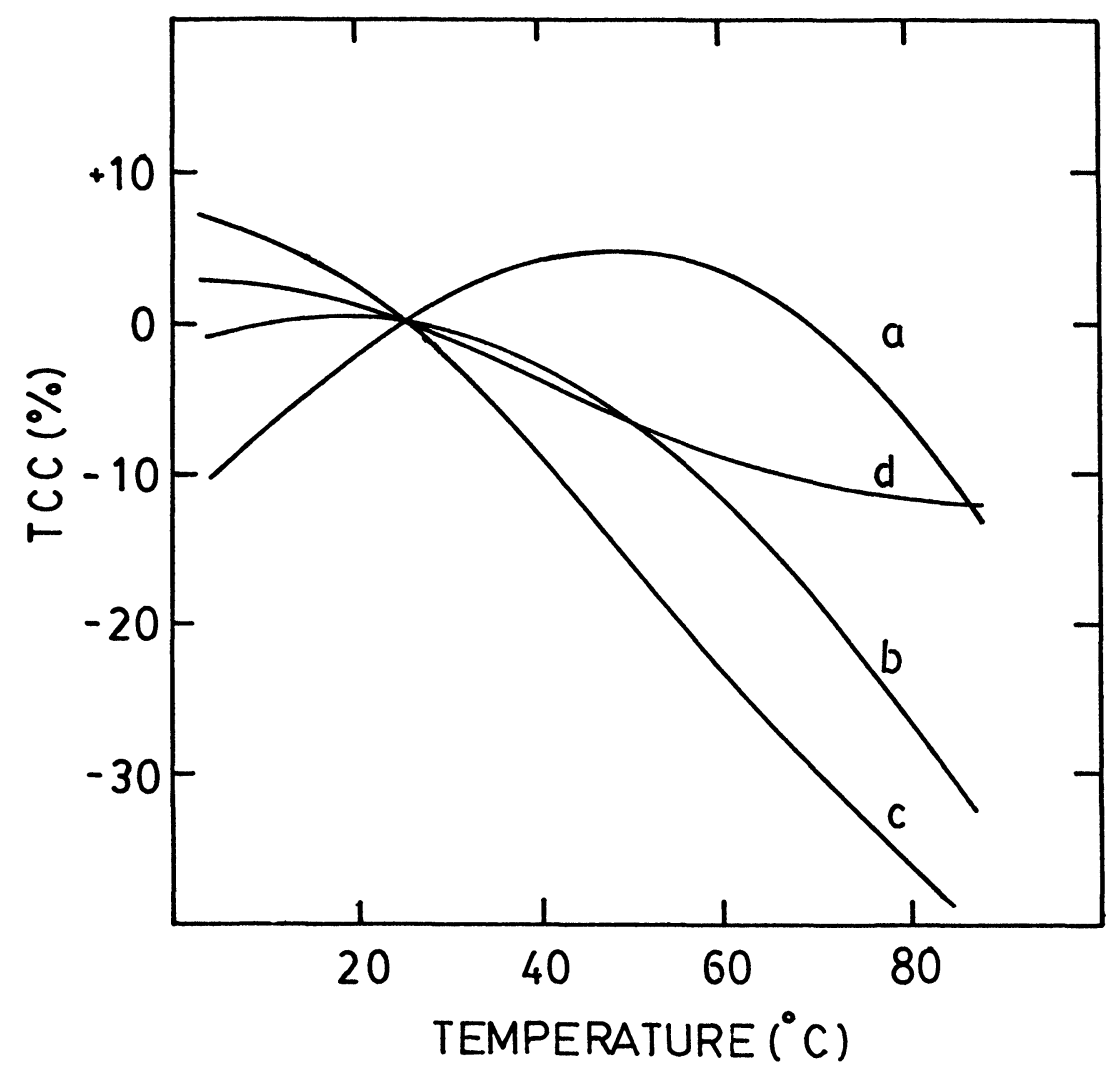

FIGURE 6 Percentage variations of capacitance (TCC) with temperature for (a) \# 1 (b) \#2 (c) \#3 and (4) \#4 at 1 KHz. 
TABLE II

Typical dielectric properties of \#1,\#2,\#3,\#4 and \#5 at room temperature.

\begin{tabular}{|l|cccc|ccc|ccc|}
\hline & \multicolumn{4}{|c|}{ capacitance density $\left(\mathrm{nF} / \mathrm{cm}^{2}\right)$} & \multicolumn{2}{|c|}{ dielectric constant } & \multicolumn{3}{|c|}{ loss factor(8) } \\
\hline & $1 \mathrm{KHz}$ & $10 \mathrm{KHz}$ & $100 \mathrm{KHz}$ & $1 \mathrm{KHz}$ & $10 \mathrm{KHz}$ & $100 \mathrm{KHz}$ & $1 \mathrm{KHz}$ & $10 \mathrm{KHz}$ & $100 \mathrm{KHz}$ \\
\hline$\# 1$ & 29 & 28 & 27.5 & 1639 & 1580 & 1556 & 3.07 & 1.93 & 1.16 \\
\hline$\# 2$ & 28.8 & 27.6 & 27 & 1630 & 1561 & 1527 & 3.5 & 1.17 & 1.13 \\
\hline$\# 3$ & 17 & 16.4 & 16 & 967 & 931 & 914 & 4.6 & 1.23 & 0.37 \\
\hline$\# 4$ & 13.8 & 13.2 & 13 & 783 & 747 & 739 & 4.9 & 1.78 & 0.53 \\
\hline$\# 5$ & 28.6 & 28.2 & 28 & 1620 & 1600 & 1575 & 0.86 & 0.86 & 0.95 \\
\hline
\end{tabular}

Note: capacitance density is calculated with dielectric thickness of $50 \mu \mathrm{m}$.

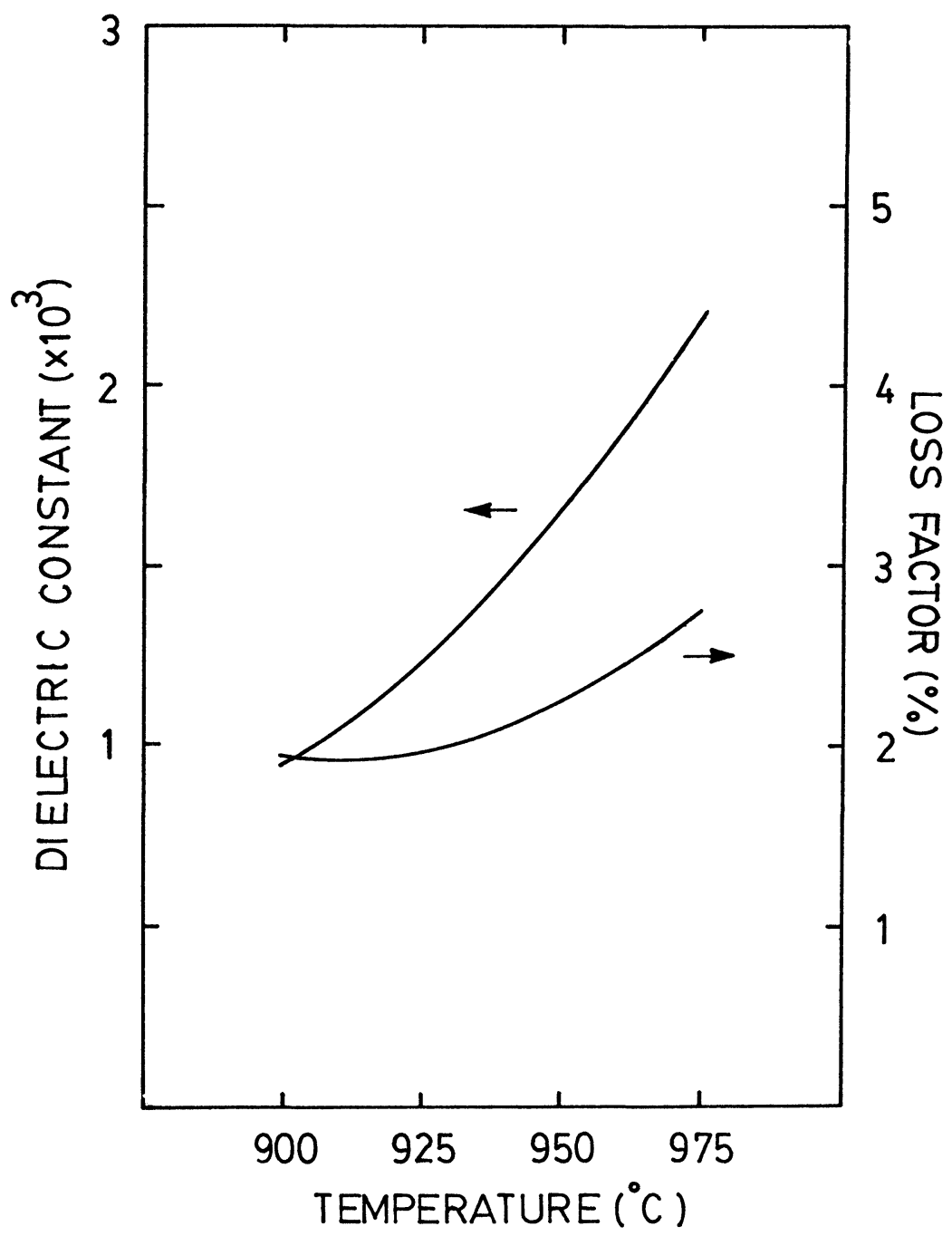

FIGURE 7 Effect of peak firing temperature on the dielectric constant and loss factor at $10 \mathrm{KHz}$. 
densification of the thick film body. The increase of loss factor with peak firing temperature may result from the grain growth and the formation of $\mathrm{Pb}$-vacancies during firing.

It can also be seen from Fig. 8, in which curves (a) and (b) are for compositions \#2 and \#5 fired at $970^{\circ} \mathrm{C}$ and curves (c) and (d) are for the same compositions fired at $900^{\circ} \mathrm{C}$, that for curves (a) and (b) the loss factor increases exponentially with temperature. The loss factor of curve (a) rises to about $10 \%$ when the temperature is $85^{\circ} \mathrm{C}$. Under this circumstance, thermal runaway can be introduced and this will deteriorate the thick film capacitor.

The addition of small amounts of $\mathrm{MnO}_{2}$ or $\mathrm{MnO}$ has been proved to be effective in overcoming such behaviour [9-12]. The incorporated $\mathrm{Mn}^{+4}$ act as trap centres to reduce the loss factor, resulting from the presence of free carriers. After incorporating $0.02 \mathrm{wt} \% \mathrm{MnO}_{2}$ into composition \#2, (shown in curve (d) in Fig. 8) the loss factor is depressed below $2 \%$ within the temperature range of $-25^{\circ}$ to $+85^{\circ} \mathrm{C}$. By comparing curve (b) and (d) in Fig. 8, which are all of composition \#5 $\left(99.98 \% \# 2+0.02 \mathrm{wt} \% \mathrm{MnO}_{2}\right)$, it can be seen that curve (d) is much lower than curve (b). Thus the model of $\mathrm{Pb}$-vacancies is feasible.

\subsection{Effect of PFW and Firing Temperature}

Fig. 9 shows dielectric constant as a function of temperature for material \#2 fired at three different temperatures. Two different peaks are seen to exist in the curves of dielectric constant against temperature. It would be advantageous if one could combine these two peaks in order to improve the TCC of the thick film capacitors. Examination of the x-ray diffraction patterns shown in Fig. 10 also confirm the existence of a double peak in dielectric constant.

In Fig. $10(a)$, there is a diffraction peak of $2 \theta=75.22^{\circ}$ for $\mathrm{PF}(\mathrm{W} / \mathrm{N}) \mathrm{T}$ with $\mathrm{x}=0.29$. When the firing temperature is increased, the relative intensity of the diffraction peak at $2 \theta=75.22^{\circ}$ is decreased, but still exists. This implies that the amount of the $\mathrm{PF}(\mathrm{W} / \mathrm{N}) \mathrm{T}$ phase is reduced and that the PFW dissolves into the $\mathrm{PF}(\mathrm{W} / \mathrm{N}) \mathrm{T}$ grains at the higher firing temperature. The additional peaks observed indicate that a second phase is generated around the grain boundaries following the diffusion of $\mathrm{PFW}$ into the $\mathrm{PF}(\mathrm{W} / \mathrm{N}) \mathrm{T}$ grains.

In Fig. 10 (b) and (c), the $2 \theta$ value of the diffraction peaks shift from $75.42^{\circ}$ to $75.20^{\circ}$ down

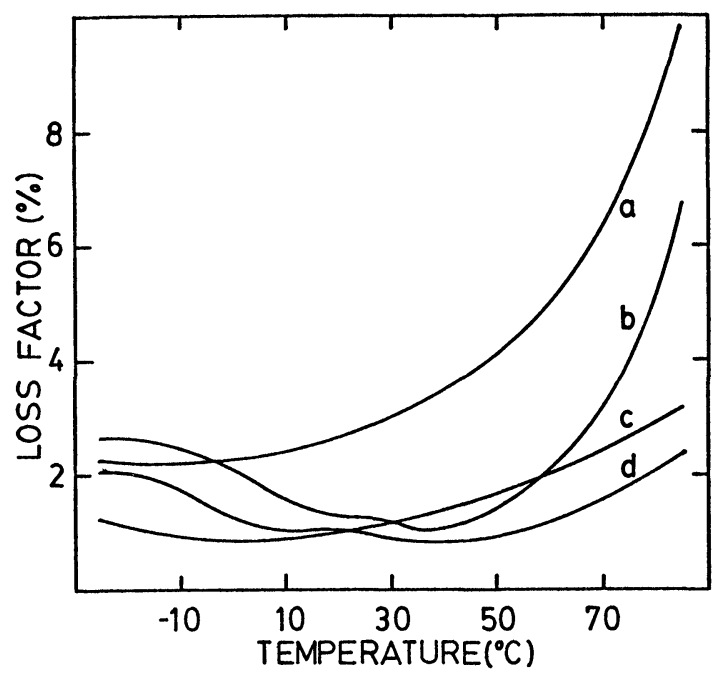

FIGURE 8 Effect of peak firing temperature and addition of $\mathrm{MnO}_{2}$ on the characteristics of loss factors (1 KHz) vs. temperature for (a) \#2 $\left(970^{\circ} \mathrm{C}\right)(\mathrm{b}) \# 5\left(970^{\circ} \mathrm{C}\right)(\mathrm{c}) \# 2\left(900^{\circ} \mathrm{C}\right)$ and $(\mathrm{d}) \# 5\left(900^{\circ} \mathrm{C}\right)$. (note: \#2 had been aged for 4 months) 


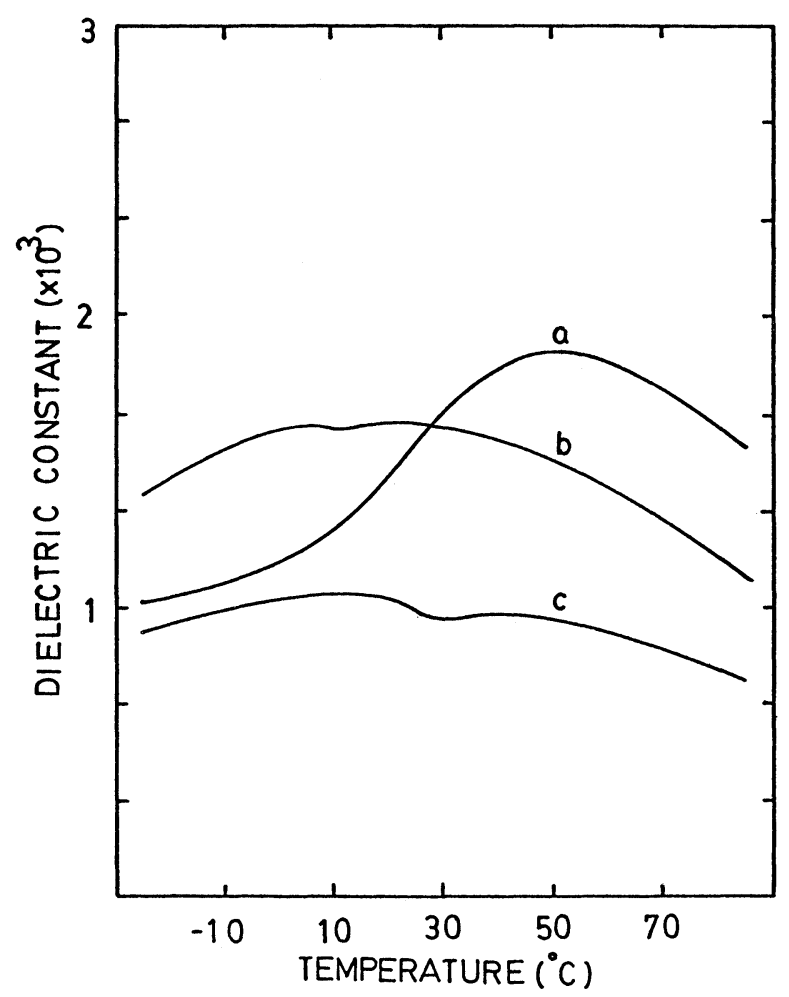

FIGURE 9 Effect of peak firing temperatures on the dielectric constants $(1 \mathrm{KHz})$ vs. temperature for \#2 with firing temperature of (a) $970^{\circ} \mathrm{C} \mathrm{(b)} 930^{\circ} \mathrm{C}$ and (c) $900^{\circ} \mathrm{C}$.

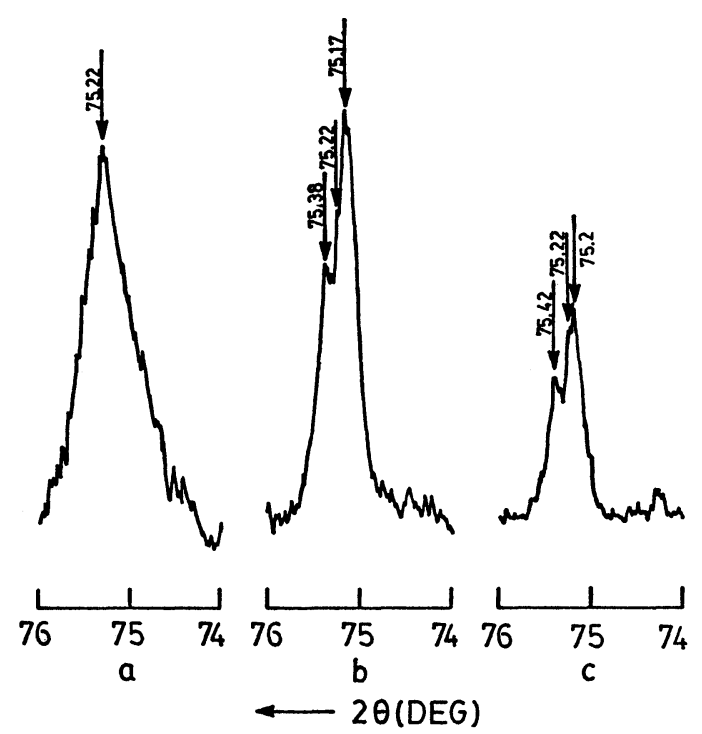

FIGURE 10 X-ray diffraction pattern with the $2 \theta$ range from $74^{\circ}$ to $76^{\circ}$ for (a) $\mathrm{PF}(\mathrm{W} / \mathrm{N}) \mathrm{T}$ with $\mathrm{x}=0.29$ (b) \#2 (fired at $900^{\circ} \mathrm{C}$ ) and (c) \#2 (fired at $930^{\circ} \mathrm{C}$ ). 
to $75.38^{\circ}$ and $75.17^{\circ}$, respectively. According to the Bragg Law $(\lambda=2 \mathrm{~d} \sin \theta)$, the decrease of $2 \theta$ values indicates an increase in the lattice constant. Since the lattice constant of PFW is larger than that of $\mathrm{PF}(\mathrm{W} / \mathrm{N}) \mathrm{T}$, the increase of lattice constant with increasing firing temperature, is evidence of the incorporation of PFW into the $\mathrm{PF}(\mathrm{W} / \mathrm{N}) \mathrm{T}$. However, in the curve (a) of Fig. 9, which is \#2 fired at $970^{\circ} \mathrm{C}$, the Curie temprature shifts upwards, unlike the results shown in curves (b) and (c). It is believed that under firing temperatures higher than $950^{\circ} \mathrm{C}$, PFW may be vaporized due to its low melting point $\left(870^{\circ} \mathrm{C}\right)$. Since the firing period is only about 15 minutes, the diffusion of $\mathrm{PFW}$ into $\mathrm{PF}(\mathrm{W} / \mathrm{N}) \mathrm{T}$ grain is also limited. Under these circumstances, PFW vaporization may be dominant, so a sharper dielectric constant versus temperature relationship and a higher Curie temperature $\left(50^{\circ} \mathrm{C}\right)$ are to be expected.

\section{CONCLUSIONS}

From the experimental results discussed above, several conclusions can be deduced as follows:-

(1) $\mathrm{PF}(\mathrm{W} / \mathrm{N}) \mathrm{T}$-based dielectric material, with $\mathrm{PFW}$ added as a flux agent and $\mathrm{MnO}_{2}$ added to improve the loss factor characteristics, can be fired at temperatures below $1000^{\circ} \mathrm{C}$. The resultant material has an average dielectric constant from 783 to 1639 at $1 \mathrm{KHz}$, and loss factor below $2 \%$ from $-25^{\circ} \mathrm{C}$ to $+85^{\circ} \mathrm{C}$.

(2) The occurrence of double peaks in the relationship of dielectric constant versus temperature, together with the examination of $x$-ray diffraction patterns, is evidence for a second phase generated by incorporating PFW into the $\mathrm{PF}(\mathrm{W} / \mathrm{N}) \mathrm{T}$. By suitably adjusting $\mathrm{PF}(\mathrm{W} / \mathrm{N}) \mathrm{T}$ and the amount of the second phase, one can obtain thick film dielectrics with good TCC characteristics.

(3) The comparatively high dielectric constant, smaller capacitance variation around room temperature and a lower loss factor, make $\mathrm{PF}(\mathrm{W} / \mathrm{N}) \mathrm{T}$-based dielectric materials very promising for thick film capacitor applications.

\section{REFERENCES}

1. K. Abe, A. Ikegami, N. Sugishita, N. Taguchi, T. Isogai, I. Tsubokawa, and H. Ohtsu, "Developement of the Thick Film Capacitor and Its Application for Hybrid Circuit Modules”, Proc. of IEEE-ECC, pp 277-285 (1979).

2. T.C. Reiley, J.V. Badding, D.A. Payne, and D.A. Chance, "A Low-Temperature Firing Thick Film Capacitor Material Based on Lead Iron-Niobate/Tungstate”, Mat. Res. Bull., Vol. 19, No. 12 pp 1543-1549 (1984).

3. G.F. Chen, M.S. Thesis, National Cheng Kung University, R.O.C., 1984.

4. S.L. Swartz, T.R. Shrout, W.A. Schulze, and L.E. Cross, "Dielectric Properties of Lead-Magnesium Niobate Ceramics", J. Amer. Ceram. Soc., Vol. 67, pp 311-315 (1984).

5. G.F. Chen and S.L. Fu, Unpublished Work.

6. G.C. Kuczynski, "A Note about So-call Activated Sintering", Proc. of the 4-th International Round Table Conference on Sintering.

7. Yu. E. Roginskaya, Yu. N. Venevtsev, and G.S. Zhdanov, "New Magnetic Ferroelectrics", Soviet Phys.-JEPT, Vol. 21, pp 817-822 (1965).

8. G.A. Smolenskii, V.A. Isupov, A.F. Agranovskaya, and S.N. Popov, "Ferroelectrics with Diffuse Phase Transitions", Soviet phys.-Solid State, Vol. 2, pp 2584-2594 (1961).

9. H. Tanei, A. Ikegami, N. Taguchi, K. Abe, H. Ohtsu, and T. Isogai, "Low temperature-sinterable Dielectric Composition and Thick Film Capacitor Using the Same", U.S. Patent, 4,308,571 (1981).

10. T.S. Shrout, S.L. Swartz, and M.J. Haun, "Dielectric Properties in the $\mathrm{Pb}\left(\mathrm{Fe}_{1 / 2} \mathrm{Nb}_{1 / 2}\right) \mathrm{O}_{3}-\mathrm{Pb}\left(\mathrm{Ni}_{1 / 3} \mathrm{Nb}_{2 / 3}\right) \mathrm{O}_{3}$ SolidSolution System", Am. Ceram. Soc. Bull., Vol. 63, pp 808-810, 820 (1984).

11. M.P. Kassarjian, R.E. Newnhum, and J.V. Biggers, "Reduction of Losses in Lead-Iron Niobate Dielectric Ceramics", Am. Ceram. Soc. Bull., Vol. 64, pp 1245-1248 (1985).

12. S.L. Fu and G.F. Chen, Unpublished work. 

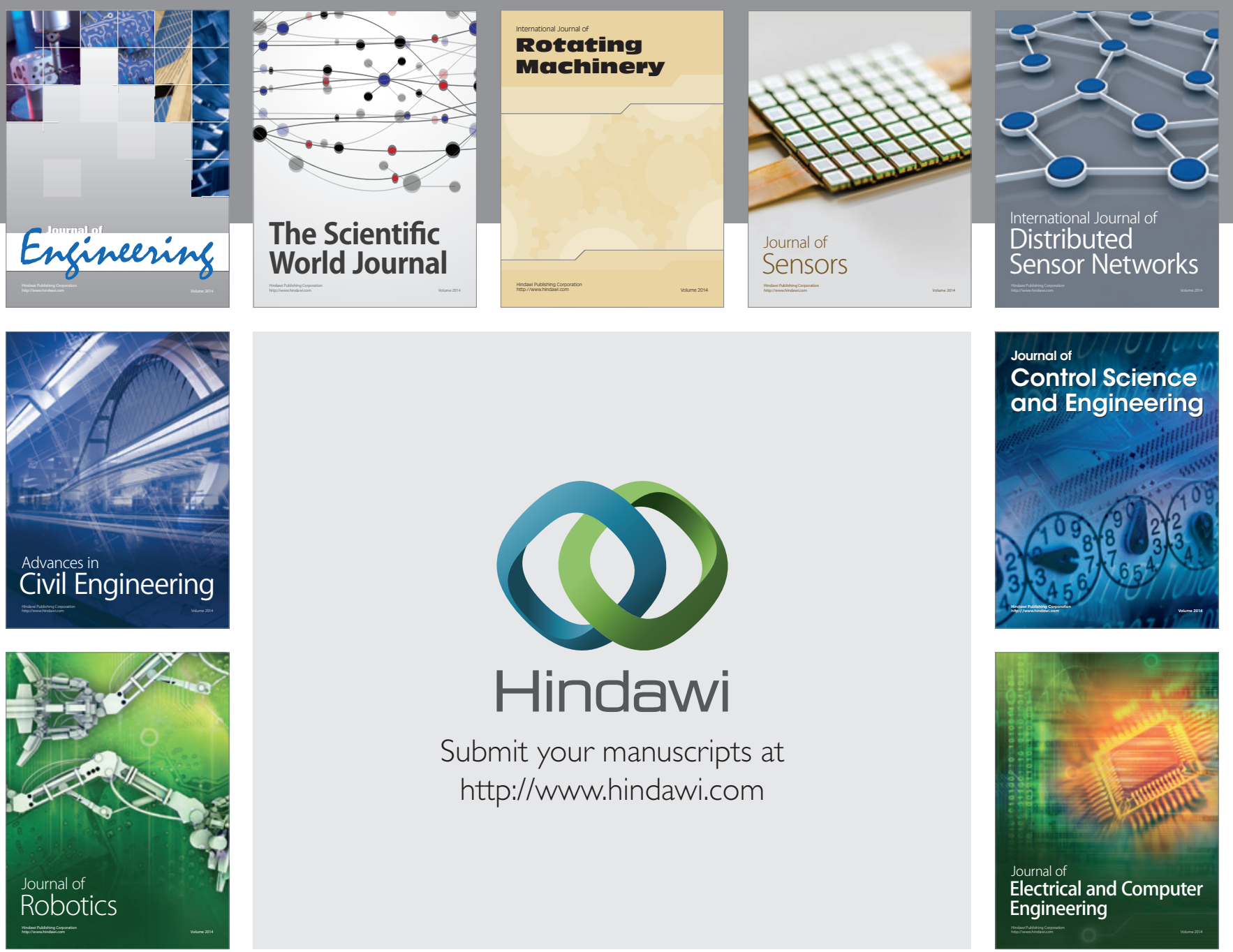

Submit your manuscripts at

http://www.hindawi.com
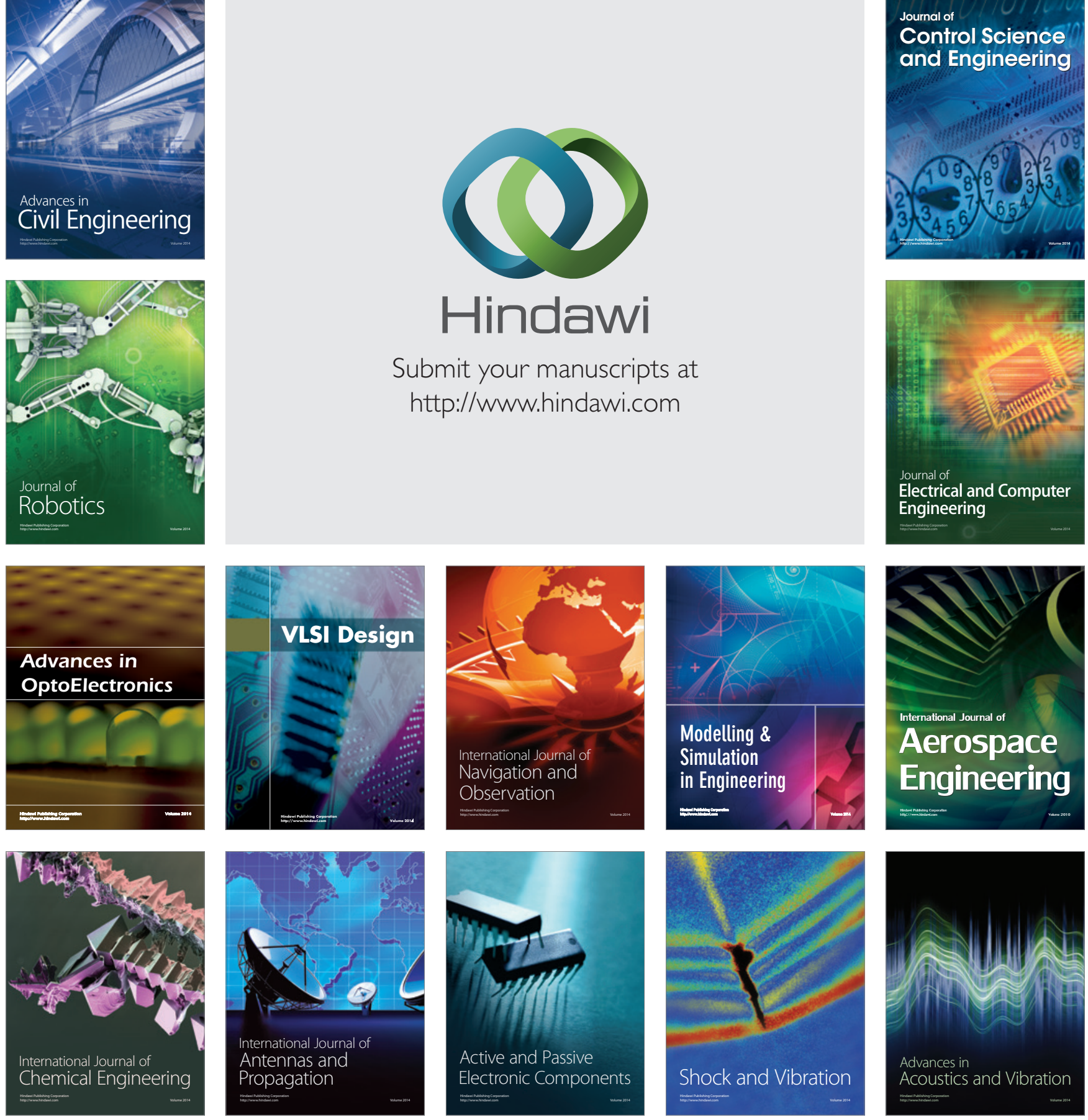